\title{
OPEN West Nile virus seroprevalence and associated risk factors among horses in Egypt
}

\author{
Abdelfattah Selim ${ }^{1}$, Ameer Megahed ${ }^{2,3}$, Sahar Kandeel $^{1}$, Abdulaziz Alouffi, ${ }^{4,5}$ \& \\ Mashal M. Almutairi ${ }^{5,6}$
}

Determination of the seroprevalence and risk factors that are associated with West Nile virus (WNV) in horses is essential for adoption of effective prevention strategies. Our objective in this study, therefore, was to determine the seroprevalence and to identify the risk factors associated with WNV infection in the most densely horse-populated governorates in Egypt. A cross-sectional study was conducted in 2018 on 930 horses, which were distributed over five governorates in the Nile delta of Egypt. The horses, which were randomly selected, were serologically tested through use of an ID screen West Nile competition enzyme-linked immunosorbent assay (ELISA) to detect anti-WNV immunoglobulin G (IgG) and plaque reduction neutralization tests (PRNT; gold standard) to confirm the seropositive status of animals and to avoid cross reaction with other flavi-viruses. Four variables (geographical location, breed, sex and age) were considered in the risk analysis. Univariable and stepwise forward multivariable logistic regression methods were used for risk-factor analysis. The odds ratio (OR) was used as an approximate measure of relative risk. A total of 156 (16.8\%; $95 \%$ confidence interval (CI) 14.4-19.2; $P<0.001$ ) serum samples were found to be serologically positive for WNV. The highest seroprevalence rate was detected in horses of age $\geq 15$ years $(68.1 \% ; 95 \% \mathrm{Cl} 49.8-72.4)$, stallions (26.4\%; 95\% Cl 22.7-30.4), and those of mixed breed (21.5\%; 95\% Cl 17.7-27.5). Horses older than 15 years were found to be at increased risk of WNV infection with $\mathrm{OR}=4.3(95 \% \mathrm{Cl} 3.0-6.2$, $P<0.001)$ compared with horses aged under 2.5 years. Also, when all the risk factors were considered, stallions were more likely than mares to be WNV seropositive $(\mathrm{OR}=2.4,95 \% \mathrm{Cl} 1.6-3.7, P<0.001)$, and of the breeds, mixed-breed $(\mathrm{OR}=1.9,95 \% \mathrm{CI} 1.2-2.8, P=0.005)$ and Arabian horses $(\mathrm{OR}=1.9$, $95 \% \mathrm{Cl} 1.2-2.8, P=0.005)$ were more likely to be seropositive. Geographical location seemed to have no impact on the seroprevalence of exposure to WNV among these horses. Due to these findings, we strongly recommend intensive surveillance and implementation of effective control and prevention strategies against WNV, especially in stallion, mixed-breed horses with ages $\geq 15$ years.

West Nile fever (WNF) is a zoonotic, widespread, vector-borne infection caused by West Nile virus (WNV), which belongs to the family Flaviviridae ${ }^{1,2}$. The disease is listed by the World Organization for Animal Health (OIE) as a notifiable disease, which means that animal owners and member countries are required to report its occurrence. West Nile virus is maintained in nature and is spread in an enzootic cycle between its biological vector (mosquitoes) and birds (primary host) ${ }^{3}$. In Egypt, Culex antennatus is the major mosquito species that is responsible for WNV transmission in the amplification cycle ${ }^{3}$. Around the world, more than 300 bird species may act as vertebrate hosts for WNV. Infected migratory birds are thought to play the major role in the spread of the virus to virus-free areas ${ }^{4}$. West Nile virus infects humans and horses through the bites of infected mosquitoes. Humans and horses are dead-end hosts that do not contribute to the spread or amplification of the virus ${ }^{5,6}$.

West Nile virus causes severe neuro-invasive illness in $1-10 \%$ of infected horses ${ }^{7}$. The typical clinical sign of infection is fever, which is followed by neurological signs such as ataxia, weakness of hind limbs, anorexia,

\footnotetext{
${ }^{1}$ Department of Animal Medicine (Infectious Diseases), Faculty of Veterinary Medicine, Benha University, Moshtohor-Toukh 13736, Kalyobiya, Egypt. ${ }^{2}$ Department of Animal Medicine (Internal Medicine), Faculty of Veterinary Medicine, Benha University, Moshtohor-Toukh 13736, Kalyobiya, Egypt. ${ }^{3}$ Department of Veterinary Clinical Medicine, College of Veterinary Medicine, University of Illinois at Urbana-Champaign, Illinois, IL 61802, USA. ${ }^{4}$ King Abdulaziz City for Science and Technology, Riyadh 12354, Saudi Arabia. ${ }^{5}$ Vaccines Research of Infectious Diseases, King Saud University, Riyadh 11495, Saudi Arabia. ${ }^{6}$ Department of Pharmacology and Toxicology, College of Pharmacy, King Saud University, Riyadh, Saudi Arabia. ${ }^{\varpi}$ email: Abdelfattah.selim@ fvtm.bu.edu.eg
} 


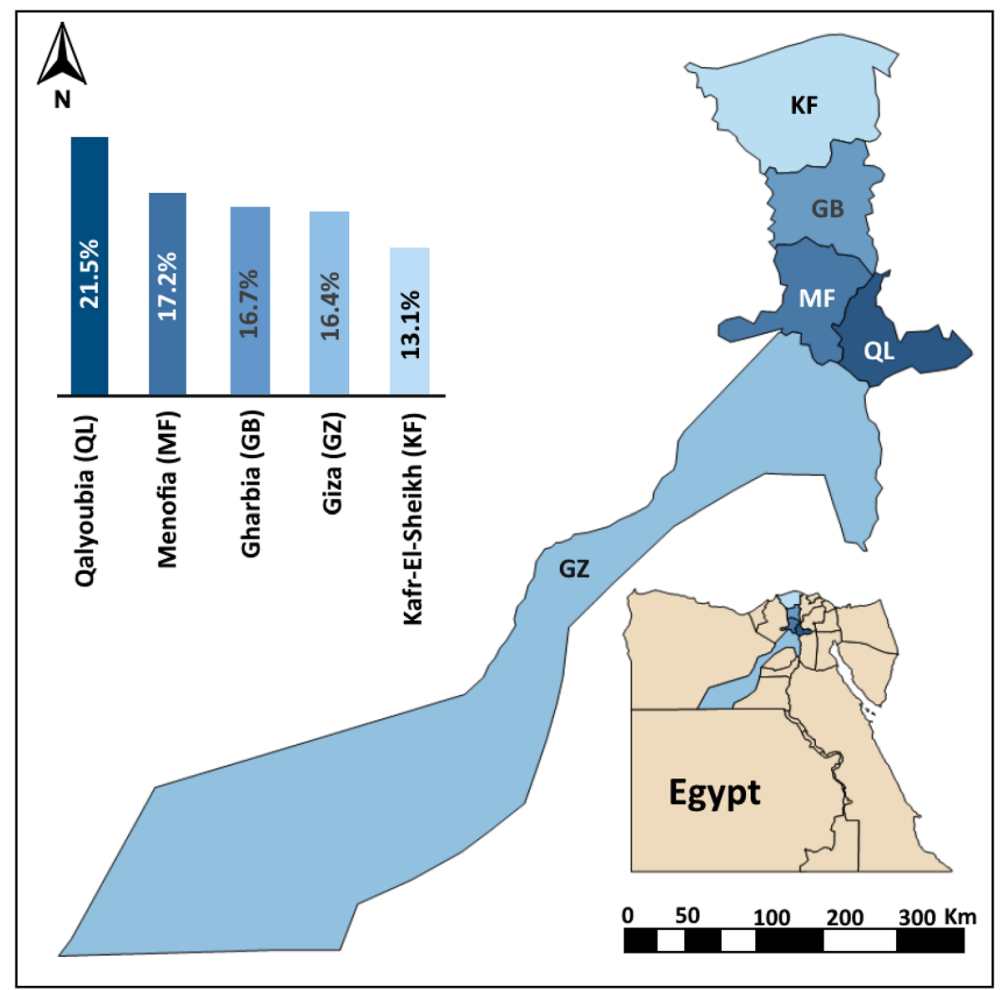

Figure 1. Distribution of West Nile virus infection (WNV) in horses of the Nile Delta of Egypt. The column graph showed the seroprevalence of WNV infection for each governorate.

depression, recumbency with an inability to rise, head pressing, signs of colic and even coma. Behaviour changes that range from aggression and hyperexcitability to somnolence may also be $\operatorname{seen}^{8-11}$.

WNV was first reported in 1937 in the West Nile region of Uganda. Since then the virus has become endemic in many African countries, as well as in the Middle East, Europe and Asia ${ }^{12}$. Recently, the disease has been reported among horses in the eastern and central regions of Saudi Arabia with a prevalence rate of $46.5 \%{ }^{13}$. Since the 1960s, sporadic cases and outbreaks of WNV infection in both humans and horses have been reported in Europe. Surveys in parts of Europe and the Middle East have shown that nearly one-third of tested horses have been exposed to WNV, even though they show no clinical signs ${ }^{7,14}$. In the United States, WNV was first reported in crows in the eastern states, and it caused a severe epidemic of meningoencephalitis among people in New York City in $1999^{15}$. Later, the virus spread throughout Central America and Canada ${ }^{4}$. WNV was first recorded in the Mediterranean basin, including Egypt and Israel, in the early $1950 \mathrm{~s}^{3,16}$. Several outbreaks among equine populations in the Mediterranean region sparked awareness of the importance of the disease and raised interest in research to predict where and when the virus would appear next ${ }^{3,17}$. However, few small-scale studies have been conducted to investigate the prevalence of WNV infection among horses in Egypt. They have reported seroprevalence that ranges from 20.7 to $25.5 \%{ }^{18,19}$.

Definition of the risk factors that lead to infection with WNV is a key to implementation of successful prevention and control strategies, and helps animal owners to decide whether or not to vaccinate horses ${ }^{20}$. Animalrelated factors such as age and breed have shown an association with the seroprevalence of exposure to WNV among horses ${ }^{21}$. However, the effect of these factors remains unclear and warrants further investigation. The main objective of this study was therefore to investigate the seroprevalence of exposure to WNV among horses that had been raised in the Nile delta of Egypt, as well as to determine the risk factors that were associated with exposure to WNV in these horses.

\section{Materials and methods}

Ethical approval. The study was performed in accordance with relevant guidelines and regulations of the Internal Ethics Review Committee of the Faculty of Veterinary Medicine, Benha University. Approval was obtained from the Faculty of Veterinary Medicine, University of Benha Animal Ethics Committee.

Blood was collected after receipt of each horse owner's informed consent; we obtained statements that implied "informed consent" of owners.

Study area. This study was carried out in five governorates (Kafr Elsheikh (KF); Gharbia (GB); Menofia (MF); Qalyoubia (QL); and Giza (GZ)). These governorates are located in the northern part of Egypt (from $38^{\circ}$ $18^{\prime} \mathrm{N}$ to $30^{\circ} 56^{\prime} \mathrm{E}, 30^{\circ} 52^{\prime} \mathrm{N}$ to $31^{\circ} 2^{\prime} \mathrm{E}, 30^{\circ} 31^{\prime} \mathrm{N}$ to $30^{\circ} 59^{\prime} \mathrm{E}, 30^{\circ} 25^{\prime} \mathrm{N}$ to $31^{\circ} 13^{\prime} \mathrm{E}$ and $30^{\circ} 01^{\prime} \mathrm{N}$ to $31^{\circ} 13^{\prime} \mathrm{E}$, respectively), as shown in Fig. 1. These governorates were selected as they were considered to be the most densely 
horse-populated areas of Egypt. The climate of these areas is hot in the summer (average $34^{\circ} \mathrm{C}$ ) and cool in the winter (average $10^{\circ} \mathrm{C}$ ), when the low temperatures are accompanied by rain. The climate of this region aids the multiplication and distribution of the vectors.

Animals and sample collection. The sample size ( 930 horses) that was used for this study was calculated to be adequate based on a calculation that involved Cochran's formula ${ }^{22}$, as follows:

$$
n=Z^{2} \frac{p(1-p)}{e^{2}}
$$

in which $\mathrm{n}$ is the sample size, $\mathrm{Z}$ is the statistic corresponding to the level of confidence, $p$ is expected prevalence, and $e$ is the precision (corresponding to effect size). The level of confidence that was used in this study was $95 \%$, the precision (e) was $5 \%$ and the expected prevalence was $20.7 \%$, based on the prevalence that had been reported in an earlier study ${ }^{18}$.

Following a cross-sectional study design, 930 healthy horses were screened for the presence of immunoglobulin G (IgG) antibodies against WNV during the late spring and summer months of 2018 . The horses were stratified by governorates according to the approximate number of horses that were understood to be in each governorate according to figures from the animal wealth development department of each governorate. Within governorates, the horses to be studied were selected randomly from different geographical locations. Most of the horses that were enrolled in this study had been raised to pull horse-drawn carriages or for horse-based tourism. Of the horses that had been raised on farms, either one or two horses were chosen randomly from each farm depending on the size of the farm. All horses had been raised in stables, whether on horse farms or by individual farmers. Horses were required to be resident in each locality at the time of sampling in order to exclude the potential of importing WNV from endemic areas.

Summaries of horse information were obtained from owners before blood was collected. Blood samples were randomly collected from 500 stallions, 300 mares and 130 geldings that ranged in age from 2 to 16 years and which had no history of vaccination or clinical signs related to WNV infection. Blood samples were collected from the jugular vein using $20 \mathrm{G}$ needles and $10 \mathrm{ml}$ blood collection tubes. Serum was collected after centrifugation of the blood samples at $1300 \times \mathrm{g} / \mathrm{min}$ for $10 \mathrm{~min}$. The serum samples were stored at $-20^{\circ} \mathrm{C}$ until serological testing could be performed.

Serological testing using ELISA. All serum samples were serologically tested for the presence of IgG antibodies against WNV using an ID screen West Nile competition enzyme-linked immunosorbent assay (ELISA) kit (IDVet, Montpellier, France) according to the manufacturer`s instructions. Infected horses retain a sufficient level of IgG antibodies for detection for one year after infection ${ }^{23}$. The optical density of samples was measured at $450 \mathrm{~nm}$ and the sample was considered positive if the sample/negative control percentage (S/N\%) was $\leq 40 \%$ and negative if $\mathrm{S} / \mathrm{N} \%$ was $>50 \%$. Additionally, the samples that were positive for WNV antibodies according to the ELISA were tested using plaque reduction neutralisation tests (PRNTs). These are considered the gold standard by the OIE to confirm their status ${ }^{24}$. PRNTs were performed using WNV (strain NY99-35261-11) and vero cells. Sera were tested using a starting dilution of 1:20. Titres were expressed as the reciprocal of serum dilutions that yielded $\mathrm{a} \geq 90 \%$ reduction in the number of plaques $\left(\mathrm{PRNT}_{90}\right)$.

Statistical analysis. The seroprevalence of WNV infection was estimated with the exact binomial confidence intervals (CIs) of $95 \%$ by use of the PROC FREQ of SAS analytical procedure. The associations of WNV infection with different risk factors were evaluated using the Cochran-Armitage trend test, and the strength of associations was evaluated through phi and Cramer's V value using the PROC FREQ of SAS analytical procedure. Correlation between the S/N\% figures produced by ELISA and the $90 \%$ PRNT titres was evaluated by application of the Passing-Bablok regression plot. Univariable and stepwise forward multivariable logistic regression were used to identify the most important risk factor(s) that were associated with WNV. The predicted probability curves were created using the logistic regression model-predicted probabilities. For stepwise forward multivariable logistic regression, the $P$-values for entry into or removal from the logistic regression models were $<0.05$. The logistic model, fitted with WNV infection as the outcome variable (present: 1, absent: 0 ), included fixed effects of the risk factors of breed (three levels: Arabian, thoroughbred, and mixed), sex (three levels: stallion, mare and gelding), age (five levels: $<2.5,2.5-<5,5-<10,10-<15, \geq 15$ years), and geographical location (five levels: KF, GB, MF, QL and GZ). The stepwise elimination process was stopped once all remaining variables were found to contribute significantly $(P<0.05)$ to the model. The fit of the multivariable logistic regression model was assessed through application of the Hosmer-Lemeshow goodness-of-fit test.

A logistic regression model predicts the log odds (logit) for outcome as an additive function of the risk factors. The odds ratio (OR) was used as an approximate measure of relative risk (the likelihood of having a positive result for IgG ELISA in an animal with a given risk factor compared with an animal without the risk factor). The $95 \%$ CIs for OR estimates were obtained as described by Lemeshow and Hosmer ${ }^{25}$. ORs of $>1$ indicate an increased risk of the outcome (seropositivity to WNV) with increasing value of risk factor, and ORs of $<1$ indicate a decreased risk of the outcome (seropositivity to WNV) with increasing value of the risk factor. Statistical analyses were performed using SAS 9.4 (SAS Inc., Cary, NC). 


\begin{tabular}{|l|l|l|l|}
\hline Variable & Category & No. of horse & Distribution (\%) \\
\hline \multirow{5}{*}{ Governorates } & Kafr-El-Sheikh & 160 & 17.2 \\
\cline { 2 - 4 } & Gharbia & 60 & 6.5 \\
\cline { 2 - 4 } & Menofia & 250 & 26.9 \\
\cline { 2 - 4 } & Qalyoubia & 130 & 14.0 \\
\cline { 2 - 4 } & Giza & 330 & 35.5 \\
\hline \multirow{4}{*}{ Breed } & Arabian & 300 & 32.3 \\
\hline & Thoroughbred & 351 & 37.7 \\
\cline { 2 - 4 } & Mixed & 279 & 30.0 \\
\hline \multirow{5}{*}{ Age (years) } & Stallion & 500 & 53.8 \\
\cline { 2 - 4 } & Mare & 300 & 32.3 \\
\cline { 2 - 4 } & Gelding & 130 & 14.9 \\
\hline & $<2.5$ & 29 & 3.1 \\
\cline { 2 - 4 } & $2.5-<5.0$ & 167 & 18.0 \\
\cline { 2 - 4 } & $5.0-<10$ & 463 & 49.8 \\
\cline { 2 - 4 } & $10.0-<15.0$ & 203 & 21.8 \\
\cline { 2 - 4 } & $\geq 15.0$ & 68 & 7.31 \\
\hline
\end{tabular}

Table 1. Descriptive analysis of variables used to predict the seroprevalence of West Nile virus infection in equine of the Nile Delta of Egypt.

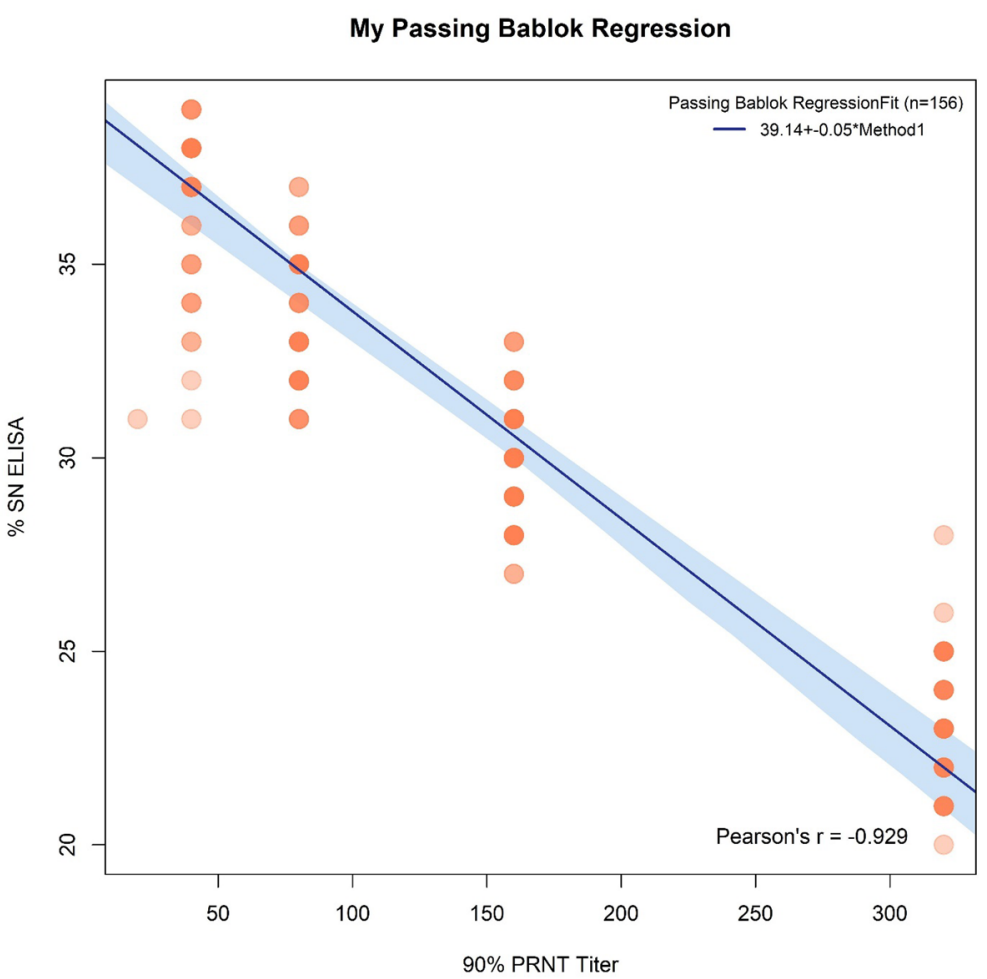

Figure 2. Correlation between SN\% of ELISA and 90\% PRNT titre.

\section{Results}

Seroprevalence of WNV. The seroprevalence of WNV infection was determined in 930 serum samples that were obtained from three different breeds of horses (Arabian, thoroughbred, and mixed) that were located in five governorates in the Nile delta of Egypt (KF, GB, MF, QL and GZ) and were of ages that ranged from 2 to 16 years. The distribution of horses based on the risk factors is illustrated in Table 1.

Of 930 tested horse serum samples, 156 sera (16.8\%) showed antibodies by indirect ELISA (95\% CI 14.4-19.2; $\mathrm{P}<0.001)$. The same horses that tested positive by ELISA $(\mathrm{n}=156)$ were positive with the PRNT. In addition, the results revealed strong correlation between the S/N\% of ELISA and 90\% PRNT titre (Pearson's correlation coefficient $=-0.93 ; \mathrm{P}<0.001$ and Spearman's rank correlation rho $=-0.91 ; \mathrm{P}<0.001)$. These results are shown in Fig. 2. 


\begin{tabular}{|c|c|c|c|c|c|}
\hline Variable & Category & No. of horses & No. positive & Prevalence (\%) & $P$ value \\
\hline \multirow{5}{*}{ Governorates } & Kafr-El-Sheikh & 160 & 21 & 13.1 & \multirow{5}{*}{0.768} \\
\hline & Gharbia & 60 & 10 & 16.7 & \\
\hline & Menofia & 250 & 43 & 17.2 & \\
\hline & Qalyoubia & 130 & 28 & 21.5 & \\
\hline & Giza & 330 & 54 & 16.4 & \\
\hline \multirow{3}{*}{ Breed } & Arabian & 300 & 40 & 13.3 & \multirow{3}{*}{0.005} \\
\hline & Thoroughbred & 351 & 54 & 15.4 & \\
\hline & Mixed & 279 & 62 & 22.2 & \\
\hline \multirow{3}{*}{ Sex } & Stallion & 500 & 132 & 26.4 & \multirow{3}{*}{$<0.001$} \\
\hline & Mare & 300 & 12 & 4.0 & \\
\hline & Gelding & 130 & 12 & 9.2 & \\
\hline \multirow{5}{*}{ Age (year) } & $<2.5$ & 29 & 0 & 0.0 & \multirow{5}{*}{$<0.001$} \\
\hline & $2.5-<5.0$ & 167 & 8 & 4.8 & \\
\hline & $5.0-<10.0$ & 463 & 31 & 6.7 & \\
\hline & $10.0-<15.0$ & 203 & 75 & 37.0 & \\
\hline & $\geq 15.0$ & 68 & 42 & 61.8 & \\
\hline
\end{tabular}

Table 2. Univariable logistic regression analysis of the association of horse-level West Nile virus infection with different risk factors in the Nile Delta of Egypt.

\begin{tabular}{|c|c|c|c|c|c|c|}
\hline Variable & Categories & $\beta$ & SE & $P$ value & OR & $95 \% \mathrm{CI}_{\mathrm{OR}}$ \\
\hline Intercept & & -8.39 & 0.98 & $<0.001$ & - & - \\
\hline \multirow{5}{*}{ Age } & $<2.5$ & Reference & & & & \\
\hline & $2.5-<5.0$ & 0.94 & 0.17 & 0.303 & 1.7 & $0.9-3.2$ \\
\hline & $5.0-<10.0$ & 0.84 & 0.14 & 0.012 & 2.3 & $1.3-6.6$ \\
\hline & $10.0-<15.0$ & 1.29 & 0.23 & $<0.001$ & 3.6 & $2.1-5.4$ \\
\hline & $\geq 15.0$ & 1.46 & 0.19 & $<0.001$ & 4.3 & $3.0-6.2$ \\
\hline \multirow{3}{*}{ Sex } & Mare & Reference & & & & \\
\hline & Stallion & 0.94 & 0.22 & $<0.001$ & 2.4 & $1.6-3.7$ \\
\hline & Gelding & 0.80 & 0.34 & 0.109 & 1.3 & $0.8-4.2$ \\
\hline \multirow{3}{*}{ Breed } & Arabian & Reference & & & & \\
\hline & Thoroughbred & 0.83 & 0.41 & 0.204 & 1.4 & $0.9-2.3$ \\
\hline & Mixed & 0.89 & 0.21 & 0.005 & 1.9 & $1.2-2.8$ \\
\hline
\end{tabular}

Table 3. Multiple stepwise logistic regression analysis of potential risk factors associate with West Nile virus seropositivity in horse in the Nile Delta of Egypt.

The results of univariable logistic regression showed that the seroprevalence of WNV infection differed nonsignificantly $(P=0.768)$ between the localities that were investigated. However, horses from the QL governorate showed the highest seroprevalence of WNV (21.5\%), followed by MF (17.2\%), GB (16.7\%), GZ (16.4\%) and KF $(13.1 \%)$, as shown in Table 2 and Fig. 1 . In contrast, the distribution of WNV positivity was dependent on age $(P<0.001)$, sex $(P<0.001)$, and breed of the horse $(P<0.01$; Table 2$)$. The results of this study showed a moderate association between the seroprevalence of exposure to WNV infection and age (phi coefficient and Cramer's $\mathrm{V}=0.56)$, and weak association with sex (0.28). However, phi coefficients/Cramer's Vs of 0.10 and 0.06 indicated that there were no associations between the seroprevalence of WNV infection and breed and geographical location, respectively.

The final model of stepwise logistic regression indicated that age, sex and breed were significant risk factors for seropositivity to WNV infection (Table 3). Geriatric horses (aged over 15 years) were 4.3 (95\% CI 3.0-6.2, $P<0.001)$ times more likely to show WNV infection than horses aged under 2.5 years; the horses that were aged over 15 years showed a $99.0 \%$ probability of being seropositive for WNV infection. Interestingly, the probability of risk increased with age, as shown in Fig. 3. Stallions were more likely to be WNV seropositive than mares $(\mathrm{OR}=2.4,95 \% \mathrm{CI} 1.6-3.7, P<0.001)$, whereas geldings were not significantly more or less likely to be seropositive than mares. Mixed-breed horses were also found to be at higher risk of exposure to WNV $(\mathrm{OR}=1.9,95 \% \mathrm{CI}$ 1.2-2.8, $P=0.005$ ) than Arabian horses, whereas thoroughbred horses were not significantly more or less likely to be seropositive than Arabian horses. However, geographical location showed no impact on the seroprevalence of WNV infection (OR=0.9, 95\% CI 0.8-1.1, $P=0.7698)$. 


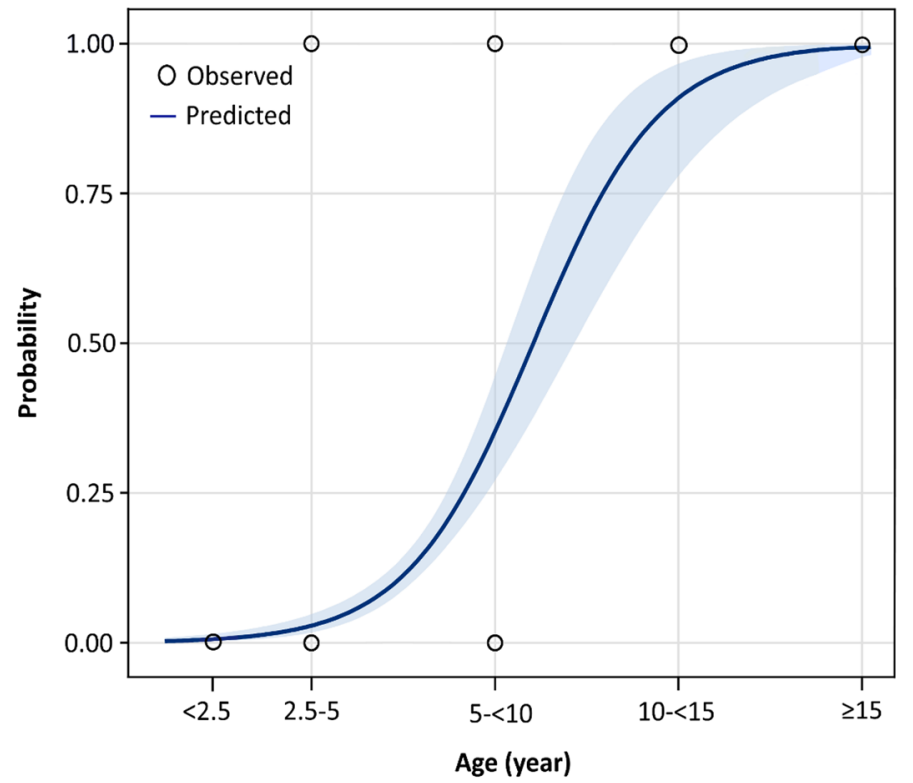

Figure 3. Probability plot for the ability of age to predict the seroprevalence of West Nile virus (WNV) infection in the Nile Delta horses in Egypt. The curve shows the likely probability of seropositive WNV associated with age, with the $95 \%$ shaded blue confidence interval.

\section{Discussion}

WNV is a mosquito-borne pathogen of global public health importance. With the rapid global spread of WNV and its endemic status in many places, WNV might spread into new geographical areas of Egypt. To the best of our knowledge, this is the first large-scale study to have investigated the seroprevalence of WNV among horses and the associated risk factors for infection of horses by WNV in Egypt. Therefore, the results of this study provide contemporary information about WNV seroprevalence and associated risk factors that can be used as a guide for the introduction of effective prevention strategies.

The major advantages of the present study were: (1) the broad context of many governorates, which places this study among the few that have examined the seroprevalence of WNV antibodies in horses across the most densely equine-populated areas in Egypt; and (2) the large number of horses that were investigated, which confers a robustness of association between variables compared with earlier Egyptian studies. The main finding of this study was that stallions of mixed breed and of ages $\geq 15$ years were the most exposed to WNV in Egypt compared with other sexes, breeds and ages of horses.

WNV has been circulating in Egypt since $1951^{16}$. Most of the earlier studies that were conducted in the country were focused on the investigation of WNV epidemiology in humans ${ }^{16,26,27}$. Recently, increased attention has been paid to the epidemiological status of WNV among horses in $\mathrm{Egypt}^{18}$. Overall, antibodies against WNV were detected in 156 of 930 (16.8\%) examined horses by ELISA and PRNT tests. Several studies have reported lack of specificity of the ELISA test in the detection of anti-WNV antibodies due to cross-reaction with other flaviviruses ${ }^{28,29}$. Therefore, the positive samples were confirmed by PRNT, which showed the same results as the ELISA tests. These results confirm that circulation of WNV occurs among Egyptian horses.

The reported seroprevalence rate concurs with other rates that have been reported for different countries: $15.08 \%$ in Poland ${ }^{30}$ and $15 \%$ in Portugal ${ }^{31}$. However, this rate is lower than that reported in countries that surround Egypt. The prevalence of exposure to WNV among horses in Israel has been reported to be $39 \%^{32} ; 24.9 \%$ in Jordan ${ }^{33} ; 26.8 \%$ in Algeria ${ }^{34} ; 31.1 \%$ in Morocco $^{35} ; 31.6 \%$ in Turkey ${ }^{36}$; and 68.7\% in Senegal ${ }^{34}$. The low level of seroprevalence of WNV that is reported in this study might be because there are few horse farms in Egypt and therefore most of the horses that were investigated in this study were individually raised. This may have decreased the chances of exposure of the horses to the virus. Additionally, one of the main factors that affects the spread of WNV infection is the environment ${ }^{26}$. High temperatures (above $30^{\circ} \mathrm{C}$ ), which are found in the Nile delta of Egypt, particularly in summer, and low amounts of rainfall during winter and spring have been associated with a reduction in mosquito activity and with limited growth in the numbers of mosquitoes ${ }^{37-41}$. Consequently, the spread of WNV among horses is decreased because the propagation of WNV in mosquitoes is temperaturedependent ${ }^{42}$. A positive association has been reported between levels of WNV in mosquitoes and occurrence of WNV epidemics, and the previous year's precipitation figures ${ }^{32,43-45}$. Other factors such as humidity, presence of local and migratory birds' nesting sites, and the vegetation index also contribute significantly to the propagation of $\mathrm{WNV}^{46}$. Furthermore, in our study the majority of samples were collected during the early summer, whereas it is known that most WNV infection usually occurs in late summer and the autumn ${ }^{33}$. The difference between seroprevalence rates of WNV that were reported in this study and those that were reported in the earlier study might also be due in part to different sampling strategies ${ }^{47}$. 
The results of the current study showed that the risk of exposure to WNV increased markedly with the horses' ages, which suggested age-related vulnerability to WNV infection. This result is consistent with those of earlier studies $^{21,48,49}$, yet there are other studies that did not show any association between the seropositivity for exposure to WNV and age ${ }^{17,30,33}$. It has been reported that older affected horses are more likely to die from WNV infection than younger animals ${ }^{50-52}$. The reason behind this positive relationship between seropositivity for exposure to WNV and age is unknown, but it might be attributable to cumulative exposure over time.

The second risk factor for exposure to WNV that was reported in this study was the sex of the animals. Our findings were in accordance with earlier findings $\mathrm{s}^{50}$, which found a higher seroprevalence for exposure to WNV among stallions than among mares or geldings. The reason for this result is unclear, but the difference may be due to culture or management; stallions are preferred for pulling large wagons and carriages, and these occupations place them at greater risk of mosquito bites than do other tasks.

Intriguingly, the mixed-breed horses showed higher seroprevalence of WNV than the Arabian and thoroughbred horses, which was in agreement with the results of an earlier study ${ }^{33}$. However, another study reported no effect of breed on the seroprevalence of exposure to WNV in horses ${ }^{30}$. The reasons for the higher WNV seroprevalence that was found in our study among mixed-breed horses, compared with other breeds, is unknown, but it could be due to different management methods. Pure-bred horses are looked after more carefully than mixed breeds and are housed in stables, whereas mixed breeds are housed outdoors, which makes them vulnerable to attack by mosquitoes ${ }^{32}$. The results of this study showed low phi coefficient and Cramer's $\mathrm{V}$ values regarding the association between WNV exposure and breed; however, breed was a significant predictor of seroprevalence of WNV infection. This might be because of the sample size effect ${ }^{53-55}$.

The main limitation of the present study was that, because it was a cross-sectional study, it could not be used to provide evidence of a cause-and-effect relationship. Longitudinal studies that involve larger sample sizes and broader geographical representation than this study are required to verify the associations that were found in this study. Other limitations were that the IgG ELISA tests showed cross-reactivity among related flaviviruses and the PRNTs showed lower sensitivity than the ELISA tests ${ }^{7}$; therefore, new technologies are required as alternatives to the usual serological tests.

\section{Conclusion}

The results of the present study confirm the presence of WNV infection among horses in Egypt and provide updated information concerning the geographical areas that are affected by the virus. Our findings indicate that intensive surveillance and implementation of effective control and prevention of WNV infection are urgently required.

Received: 4 June 2021; Accepted: 5 October 2021

Published online: 22 October 2021

\section{References}

1. Benjelloun, A., El Harrak, M. \& Belkadi, B. West Nile disease epidemiology in North-West Africa: Bibliographical review. Transbound. Emerg. Dis. 63, e153-e159 (2016).

2. Selim, A. \& Abdelhady, A. The first detection of anti-West Nile virus antibody in domestic ruminants in Egypt. Trop. Anim. Health Prod. 52, 3147-3151 (2020).

3. Schmidt, J. R. \& Mansoury, H. K. E. Natural and experimental infection of Egyptian equines with West Nile virus. Ann. Trop. Med. Parasitol. 57, 415-427 (1963).

4. Komar, N. et al. Experimental infection of North American birds with the New York 1999 strain of West Nile virus. Emerg. Infect. Dis. 9, 311 (2003).

5. Bunning, M. L. et al. Experimental infection of horses with West Nile virus. Emerg. Infect. Dis. 8, 380 (2002).

6. Engler, O. et al. European surveillance for West Nile virus in mosquito populations. Int. J. Environ. Res. Public Health 10, 4869-4895 (2013).

7. Beck, C. et al. Improved reliability of serological tools for the diagnosis of West Nile fever in horses within Europe. PLoS Neglected Trop. Diseases 11, e0005936 (2017).

8. Spickler, A. R. West Nile Virus Infection. (2013). http://www.cfsph.iastate.edu/Factsheets/pdfs/west_nile_fever.

9. Byas, A. D. \& Ebel, G. D. Comparative pathology of West Nile virus in humans and non-human animals. Pathogens 9, 48 (2020).

10. Constable, P. D., Hinchcliff, K. W., Done, S. H. \& Grünberg, W. Veterinary Medicine-e-Book: A Textbook of the Diseases of Cattle, Horses, Sheep, Pigs and Goats (Elsevier Health Sciences, 2016).

11. Belgrave, R. L. in Robinson's Current Therapy in Equine Medicine 7th Ed. (eds K.A. Sprayberry \& N. Edward Robinson) $152-154$ (W.B. Saunders, 2015).

12. Rappole, J. H. \& Hubálek, Z. Migratory birds and West Nile virus. J. Appl. Microbiol. 94, 47-58 (2003).

13. Hemida, M. G. et al. West Nile virus infection in horses in Saudi Arabia (in 2013-2015). Zoonoses Public Health 66, 248-253 (2019).

14. Sule, W. F. et al. Epidemiology and ecology of West Nile virus in sub-Saharan Africa. Parasit. Vectors 11, 1-10 (2018).

15. Eidson, M. et al. Crow deaths as a sentinel surveillance system for West Nile virus in the northeastern United States, 1999. Emerg. Infect. Dis. 7, 615 (2001).

16. Murgue, B., Zeller, H. \& Deubel, V. Japanese Encephalitis and West Nile Viruses 195-221 (Springer, 2002).

17. Durand, B. et al. West Nile virus outbreak in horses, southern France, 2000: Results of a serosurvey. Emerg. Infect. Dis. 8, 777 (2002).

18. Selim, A., Radwan, A., Arnaout, F. \& Khater, H. The Recent update of the situation of West Nile Fever among Equids in Egypt after three decades of missing information. Pakistan Vet. J. 40, 390-393 (2020).

19. Selim, A., Radwan, A. \& Hamouda, F. Seroprevalence and molecular characterization of West Nile Virus in Egypt. Compar. Immunol. Microbiol. Infect. Diseases. 71, 101473 (2020).

20. Rainham, D. G. Ecological complexity and West Nile virus. Can. J. Public Health 96, 37-40 (2005).

21. Ahmadnejad, F. et al. Spread of West Nile virus in Iran: A cross-sectional serosurvey in equines, 2008-2009. Epidemiol. Infect. 139, 1587-1593 (2011).

22. Fleiss, J. L. Balanced incomplete block designs for inter-rater reliability studies. Appl. Psychol. Meas. 5, 105-112 (1981).

23. Joó, K. et al. Comparison of assays for the detection of West Nile virus antibodies in equine serum after natural infection or vaccination. Vet. Immunol. Immunopathol. 183, 1-6 (2017). 
24. Lefrancois, T. et al. West Nile virus in Guadeloupe: Introduction, spread, and decrease in circulation level: 2002-2005. Ann. N. Y. Acad. Sci. 1081, 206-215 (2006).

25. Lemeshow, S. \& Hosmer, D. W. Jr. Estimating odds ratios with categorically scaled covariates in multiple logistic regression analysis. Am. J. Epidemiol. 119, 147-151 (1984).

26. Soliman, A. et al. Studies on West Nile virus infection in Egypt. J. Infect. Public Health 3, 54-59 (2010).

27. Taylor, R., Work, T., Hurlbut, H. \& Rizk, F. A study of the ecology of West Nile Virus in Egypt1. Am. J. Trop. Med. Hyg. 5, 579-620 (1956).

28. Bernabeu-Wittel, M. et al. West Nile virus past infections in the general population of Southern Spain. Enferm. Infecc. Microbiol. Clin. 25, 561-565 (2007).

29. Holmes, D. A., Purdy, D. E., Chao, D.-Y., Noga, A. J. \& Chang, G.-J.J. Comparative analysis of immunoglobulin M (IgM) capture enzyme-linked immunosorbent assay using virus-like particles or virus-infected mouse brain antigens to detect IgM antibody in sera from patients with evident flaviviral infections. J. Clin. Microbiol. 43, 3227-3236 (2005).

30. Bażanów, B. et al. A survey on West Nile and Usutu viruses in horses and birds in Poland. Viruses 10, 87 (2018).

31. Barros, S. C. et al. West Nile virus in horses during the summer and autumn seasons of 2015 and 2016, Portugal. Vet. Microbiol. 212, 75-79 (2017).

32. Aharonson-Raz, K. et al. Spatial and temporal distribution of West Nile virus in horses in Israel (1997-2013)-From endemic to epidemics. PLOS ONE 9, e113149 (2014).

33. Abutarbush, S. \& Al-Majali, A. West Nile virus infection in horses in Jordan: Clinical cases, seroprevalence and risk factors. Transbound. Emerg. Dis. 61, 1-6 (2014).

34. Davoust, B. et al. Serological survey of West Nile virus in domestic animals from Northwest Senegal. Vector-Borne Zoonotic Diseases 16, 359-361 (2016).

35. Benjelloun, A. et al. Seroprevalence of West Nile virus in horses in different Moroccan regions. Vet. Med. Sci. 3, 198-207 (2017).

36. Ozkul, A. et al. Concurrent occurrence of human and equine West Nile virus infections in Central Anatolia, Turkey: The first evidence for circulation of lineage 1 viruses. Int. J. Infect. Dis. 17, e546-e551 (2013).

37. Elhaig, M. M., Selim, A., Mandour, A. S., Schulz, C. \& Hoffmann, B. Prevalence and molecular characterization of peste des petits ruminants virus from Ismailia and Suez, Northeastern Egypt, 2014-2016. Small Rumin. Res. 169, 94-98 (2018).

38. Selim, A. \& Ali, A.-F. Seroprevalence and risk factors for C. burentii infection in camels in Egypt. Compar. Immunol. Microbial. Infect. Diseases 68, $101402(2020)$.

39. Selim, A., Manaa, E. \& Khater, H. Seroprevalence and risk factors for lumpy skin disease in cattle in Northern Egypt. Trop. Anim. Health Prod. 53, 1-8 (2021).

40. Selim, A., Manaa, E. A., Alanazi, A. D. \& Alyousif, M. S. Seroprevalence, risk factors and molecular identification of bovine leukemia virus in Egyptian Cattle. Animals 11, 319 (2021).

41. Selim, A., Megahed, A. A., Kandeel, S. \& Abdelhady, A. Risk factor analysis of bovine leukemia virus infection in dairy cattle in Egypt. Compar. Immunol. Microbiol. Infect. Diseases 72, 101517 (2020).

42. Reisen, W. K. et al. Overwintering of West Nile virus in southern California. J. Med. Entomol. 43, 344-355 (2014).

43. Brugueras, S. et al. Environmental drivers, climate change and emergent diseases transmitted by mosquitoes and their vectors in southern Europe: A systematic review. Environ. Res. 191, 110038 (2020).

44. Paz, S. The West Nile Virus outbreak in Israel (2000) from a new perspective: The regional impact of climate change. Int. J. Environ. Health Res. 16, 1-13 (2006).

45. Ruiz, M. O. et al. Local impact of temperature and precipitation on West Nile virus infection in Culex species mosquitoes in northeast Illinois, USA. Parasit. Vectors 3, 19 (2010).

46. Conte, A. et al. Spatio-temporal identification of areas suitable for West Nile disease in the Mediterranean Basin and Central Europe. PLoS ONE 10, e0146024 (2015).

47. Tanner, J. M. et al. Evaluation of factors associated with positive IgM capture ELISA results in equids with clinical signs compatible with West Nile virus infection: 1017 cases (2003). J. Am. Vet. Med. Assoc. 228, 414-421 (2006).

48. Hasbun, R. et al. West Nile virus retinopathy and associations with long term neurological and neurocognitive sequelae. PLoS ONE 11, e0148898 (2016).

49. Weiss, D. et al. Clinical findings of West Nile virus infection in hospitalized patients, New York and New Jersey, 2000. Emerg. Infect. Dis. 7, 654 (2001).

50. Epp, T., Waldner, C., West, K. \& Townsend, H. Factors associated with West Nile virus disease fatalities in horses. Can. Vet. J. 48, 1137 (2007).

51. Salazar, P. et al. Outcome of equids with clinical signs of West Nile virus infection and factors associated with death. J. Am. Vet. Med. Assoc. 225, 267-274 (2004).

52. Schuler, L. A., Khaitsa, M. L., Dyer, N. W. \& Stoltenow, C. L. Evaluation of an outbreak of West Nile virus infection in horses: 569 cases (2002). J. Am. Vet. Med. Assoc. 225, 1084-1089 (2004).

53. Masenga, S. K. et al. Type 2 diabetes mellitus prevalence and risk scores in treated PLWHIV: A cross-sectional preliminary study. BMC. Res. Notes 12, 1-7 (2019).

54. Selim, A., Yang, E., Rousset, E., Thiéry, R. \& Sidi-Boumedine, K. Characterization of Coxiella burnetii strains from ruminants in a Galleria mellonella host-based model. New Microbes New Infect. 24, 8-13 (2018).

55. Selim, A., El-Haig, M. \& Galila, E. S. Direct detection of Mycobacterium avium subsp. Paratuberculosis in bovine milk by multiplex real-time PCR. Anim. Sci. Papers Rep. 31, 291-302 (2013).

\section{Author contributions}

A.S., A.M.,A.A., M.A. and S.K. designed the study and conception of the research idea; A.S., sampling collection and performed the laboratory work. A.S. and A.M. shared in data analysis. A.S., A.M., S.K., A.A. and M.A. wrote and pre-pared the manuscript for publication and revision. All authors read and approved the final manuscript.

\section{Competing interests}

The authors declare no competing interests.

\section{Additional information}

Correspondence and requests for materials should be addressed to A.S.

Reprints and permissions information is available at www.nature.com/reprints.

Publisher's note Springer Nature remains neutral with regard to jurisdictional claims in published maps and institutional affiliations. 
(c) (i) Open Access This article is licensed under a Creative Commons Attribution 4.0 International cc) License, which permits use, sharing, adaptation, distribution and reproduction in any medium or format, as long as you give appropriate credit to the original author(s) and the source, provide a link to the Creative Commons licence, and indicate if changes were made. The images or other third party material in this article are included in the article's Creative Commons licence, unless indicated otherwise in a credit line to the material. If material is not included in the article's Creative Commons licence and your intended use is not permitted by statutory regulation or exceeds the permitted use, you will need to obtain permission directly from the copyright holder. To view a copy of this licence, visit http://creativecommons.org/licenses/by/4.0/.

(C) The Author(s) 2021 